keep in close touch with the Regional Postgraduate Dean. Most Regional Postgraduate Committees have a sub-committee for psychiatry and the Regional Adviser is normally a member or may be Chairman of this committee. He will, therefore, be involved in the supervision of senior registrars, the provision of postgraduate courses, and in giving advice to recruits to psychiatry and on any educational problem encountered by a psychiatrist in training.

4. The Regional Adviser will normally be involved in the Recognition of psychiatric tutors and may wish to hold regular meetings of psychiatric tutors, specialty tutors, and course organizers in his Region. He will also be aware of rotational training schemes in the Region and can assist in the development of such rotations.

5. The Regional Adviser will be involved in College Approval visits and in Inspection visits made by the Joint Committee on Higher Psychiatric Training.

6. Regional Advisers are expected to keep in close touch with the work of the College Division and be members of the Executive Committee of the Division.

7. In addition to these educational functions, Regional Advisers in England and Wales will be consulted by the Regional Health Authorities over the job descriptions of new and replacement consultant posts. In order to assist Regional Advisers, the College Sections have produced (or are producing) guidelines for job descriptions in the psychiatric specialties and some Sections have nominated representatives in the Regions who may be consulted about job descriptions by the Regional Adviser. Section representatives will not, however, be expected to give direct advice to Health Authorities.

8. Regional Advisers may be consulted by Regional Health Authorities on other aspects of the provision of psychiatric services and should be able to indicate College policy. He should also inform the College of major local developments and problems. It is important, however, that this function of the Regional Adviser does not conflict with the role of the College Division and its office bearers and of the medical advisory structure which exists within Regional and District Health Authorities.

9. Regional Advisers should report briefly each year to the Court of Electors on their activities and developments in their Region. Minutes of the Meeting of Regional Advisers would be sent to the Court of Electors.

10. In order to avoid confusion it should be noted that the College Regional Adviser does not fulfil the function of Adviser in the Region on Merit Awards, for which an entirely different system of appointment exists.

11. Regional Advisers have Deputies who will act on their behalf in their absence. Deputies should not, however, be regarded as alternative sources of advice to Regional Health Authorities without the Regional Adviser's knowledge.

12. Regional Advisers are also responsible for nominating a College representative to serve on appointment committees for senior registrars in England and Wales.

\title{
Southern Division Trainees' Day
}

Alyson Hall, Julie Hollyman and Chris Thompson, Southern Division Representatives of the Collegiate Trainees Committee

The third Trainees' Day of the Southern Division took place on 31 March 1982 and was held for the first time in the S.E. Region, at King's College Hospital. We chose topics which are often neglected in peripheral hospitals, but were disappointed to find that trainees from these hospitals were under-represented.

The day was divided into three sections. In the morning five speakers, including two trainees, gave talks on aspects of liaison psychiatry under the chairmanship of Professor $\mathbf{R}$. Cawley. Chris Bass discussed his work on psychogenic chest pain and was followed by Paul Robinson who described psychotherapy groups for post-infarction patients. Rachel Rosser talked about groups for psychogenic breathlessness. Professor Crisp then gave a talk on bereavement, and finally, Heinz Wolff described some psychodynamic aspects of liaison psychiatry.

The afternoon opened with the participants dividing into three groups to discuss training links with medicine, with psychoanalysis, and general training problems. The liaison group demonstrated an overriding feeling of anger at the appalling training which was available in this specialty, even in the major teaching centres. Many felt that where there was experience there was inadequate supervision. Although 'overdoses' should not be entirely removed from the trainces' experience, most felt that presently they constitute far too much of it.

The general training group felt that too many consultants were not equipped as teachers. They also felt that clinical tutors ought to be elected by the trainees, rather than appointed by the consultants. The majority thought the College ought to be stricter in its criteria for granting Approval. It was recognized that the Approval Exercise had so far been successful, but that it is now necessary to go further. Senior registrars felt they suffered from isolation from other trainees and most would have liked a personal tutor, especially from the point of view of career guidance. 
Unfortunately, the representation of trainees at hospital level is still poor, which reflects a lack of organization of juniors within their hospitals.

The psychotherapy group found that the availability of supervision varied from place to place and was not always best in the teaching hospitals, of which we have four in this Division. A majority felt that the teaching of basic concepts was most important at registrar level. A few trainees were having personal analysis, and there was some concern about the ambivalent or negative attitudes towards personal therapy which are held by some senior psychiatrists.

The final session was a panel discussion about the relevance of psychotherapy training to general psychiatrists with an eminent panel representing divergent opinions, although with a surprising level of agreement. John Cobb took an eclectic view and supported this with a survey of local consultant opinion. John Sklar felt that Balint groups were an appropriate way of providing psychoanalytic training.
Heinz Wolff emphasized the need to further a trainee's personal understanding of the patient and his relationships, while Tony Clare thought the common features of the various therapies, for example interviewing skills, should be taught.

In general this was a successful day with about seventy trainees present. However, we were disappointed about three aspects. Very few trainees attending were from outside the teaching hospitals. Despite inviting all clinical tutors of the region, only the tutor from the host hospital came. We also wrote to the tutors individually asking them to allow their trainees time off to attend, but many trainees felt unable to ask for this, while others found the courage to ask but were rebuffed. We consider trainees' days to be a most important College activity, and tutors should be encouraged to arrange time off for at least some of their trainees, and should also attend themselves.

\section{Some Prize-Winning Films on Mental Health Notes from the Audio-Visual Sub-Committee}

\section{T. L. Pilknngton, Honorary Secretary, Audio-Visual Sub-Committee}

For the past 25 years the British Medical Association has held an annual film competition. In 1981, 98 films were entered and the following were among the successful ones.

Steppting Out (Colour, sound, 49 mins, Australia 1980)

This film, made for the International Year of the Disabled, is a documentary account of the rehearsals and ultimate public performance in dance and mime at the Sydney Opera House by a group of mentally handicapped persons. It is a beautiful film, sensitively produced, and one which will provoke considerable public sympathy. Its use of film techniques-slow motion music, visual symbolism, etc.-is outstanding, and it is easy to see why it won one of the only two Gold Awards.

Its teaching and clinical values are more limited. The residents in the Sunshine Home seem to include a large proportion of young adults with Down's syndrome and the star appears to be only mildly subnormal with an unusual talent for mime. Nevertheless it is a compelling film that should move even hardbitten fifth year medical students and registrars in training! Made by the Binnaburra Film Company with considerable Government and private sponsorship, it is available on film or video cassette (all formats) from Concord Films Council, 201 Felixstowe Road, Ispwich LP3 9BJ.

The Ghost in the Machtne (Colour, sound, $16 \mathrm{mins}, 20 \mathrm{~mm}$, UK 1981)

The subjects of this film are body-mind links and possible neuro-anatomical bases for depression and anxiety states. These form the background to psycho-pharmacological approaches to therapy, and various sophisticated laboratory monitoring techniques are demonstrated.

This is a colourful film with pace and style and which was given a Bronze Award. Its comparative objectivity makes it a valuable teaching film and its graphic expositions are particularly clear, e.g., on the physiology of the autonomic nervous system. It was made by Medi-Cine Productions (with specialist advice from E. Paykel, W. Poldinger, S. Checkley and R. Wilkins) for Hoechst UK and is available from the BMA Film Library, BMA House, Tavistock Square, London WC1H 9JP.

Observing Tardtive Dysktnesia (Colour, sound, $16 \mathrm{~mm}, 15$ mins, UK 1981)

The various clinical forms and degrees of dyskinesia are shown to underline the need for careful monitoring of neuroleptic drugs. This is a deceptively simple description of what is a very perceptive exercise in clinical recording. It is a wellbalanced and convincing film that holds attention throughout, and can be thoroughly recommended for its teaching value. It won a Bronze Award.

It was made in Newcastle upon Tyne by $\mathrm{Dr} \mathrm{H}$. McClelland in association with the Audio-Visual Centre Medical School, The University, Newcastle upon Tyne NE1 7RU, from whom it can be borrowed. 